\title{
SISTEM PENDUKUNG KEPUTUSAN SELEKSI PENERIMAAN STAFF ADMINISTRASI MENGGUNAKAN METODE PROFILE MATCHING
}

\author{
Agung Deni Wahyudi \\ Sistem Informasi, STMIK Teknokrat \\ Jl. Zainal Abidin Pagaralam, No 9-11, Labuhanratu, Bandarlampung \\ Email: agungwahyudi57@gmail.com
}

\begin{abstract}
Abstrak
Proses seleksi dalam penerimaan karyawan masih mengalami kendala. Secara praktikal terdapat beberapa karyawan yang tidak benar benar menguasai apa yang mereka kerjakan sehingga kegiatan operasional kurang berjalan dengan baik. Selain itu banyaknya pelamar yang ada membuat bagian terkait memerlukan waktu yang lama dalam mempertimbangkan calon karyawan yang akan diterima. Dalam ilmu komputer terdapat suatu sistem yang dapat membantu pengambil keputusan untuk mengatasi masalah yang sifatnya semi struktur ataupun tidak terstruktur yaitu sistem pendukung keputusan. Dalam Sistem Pendukung Keputusan terdapat berbagai metode salah satunya yaitu metode Profile Matching. Profile Matching ini sendiri dapat membantu dalam menentukan prioritas dari beberapa kriteria dengan melakukan analisa dari masingmasing kriteria yang sudah ditentukan. Dengan melihat masalah yang ada dalam pengambilan keputusan dalam penerimaan karyawan baru, sistem pendukung keputusan dengan menggunakan metode Profile Matching dirasa tepat untuk digunakan dalam membantu pengambilan keputusan. Dengan adanya penelitian ini proses seleksi karyawan baru dapat dilakukan dengan tepat dan cepat.
\end{abstract}

Kata Kunci : Seleksi Karyawan, Ilmu Komputer, Sistem Pendukung Keputusan, Metode Profile Matching.

\section{Pendahuluan}

Salah satu elemen dalam perusahaan yang sangat penting adalah Sumber Daya Manusia (SDM). Pengelolaan SDM dari suatu perusahaan sangat mempengaruhi banyak aspek penentu keberhasilan kerja dari perusahaan tersebut.

Jika SDM dapat diorganisir dengan baik dengan menempatkan manusia dengan latar belakang kemampuannya pada posisi yang tepat maka diharapkan perusahaan dapat menjalankan semua proses usahanya dengan lebih baik.
Pada era sekarang ini banyak sekali calon pekerja dengan latar belakang pendidikan yang sama akan tetapi belum tentu sesuai dengan jabatan/posisi yang dibutuhkan. Dengan latar belakang pendidikan yang sama belum tentu mereka memiliki keahlian yang sama.

Rekrutmen adalah upaya pencarian sejumlah calon karyawan yang memenuhi syarat dalam jumlah tertentu sehingga dari mereka perusahaan dapat menyeleksi orang orang yang paling tepat untuk mengisi lowongan yang ada.[Schuler 1997]

Tujuan utama dari proses seleksi adalah untuk mendapatkan orang yang tepat bagi suatu jabatan tertentu, sehingga orang tersebut mampu bekerja secara optimal dan mengerti apa yang seharusnya dia kerjakan sehingga orang tersebut dapat bertahan di perusahaan untuk waktu yang lama.

Meskipun tujuannya terdengar sangat sederhana, proses penempatan karyawan baru tersebut ternyata sangat kompleks, memakan waktu cukup lama dan biaya yang tidak sedikit dan sangat terbuka peluang untuk melakukan kesalahan dalam menentukan orang yang tepat hal tersebut dikarenakan banyaknya jumlah pelamar yang rata rata mencapai 25 orang dalam satu waktu perekrutan dimana yang dibutuhkan hanya 1 atau 2 orang saja.

Penilaian kompetensi calon karyawan akan mendeskripsikan kemampuan SDM sesuai dengan unit kerjanya. Adapun kompetensi itu sendiri akan merupakan kombinasi dari pengetahuan, keterampilan, sikap, dan perilaku yang dimiliki calon karyawan agar dapat melaksanakan tugas dan peran pada jabatan yang diduduki secara produktif dan professional, pada PT. General Agromesin Lestari hal tersebut dikenal dengan program P2K (Pemetaan Potensi Karyawan) sebagai usaha untuk memetakan potensi karyawan.

Pada penelitian ini penulis memberikan solusi dalam penyeleksian karyawan baru dengan menggunakan metode Profile Matching, dimana Profile Matching merupakan proses membandingkan antara kompetensi individu ke dalam kompetensi jabatan sehingga dapat diketahui perbedaan kompetensinya yang juga sering disebut dengan gap, 
semakin kecil gap yang dihasilkan maka bobot nilainya semakin besar untuk karyawan dapat menempati posisi tersebut.

\section{Pembahasan}

Dalam penyeleksian calon karyawan baru dengan metode profile matching diperlukan kriteria, kategori dan bobot untuk melakukan perhitungan. Dalam kasus ini kriteria dibagi menjadi tiga, yaitu kecerdasan, sikap kerja dan perilaku. Setiap kriteria memiliki sub kriteria dan nilai target. Untuk kategori ada dua sub, core factor dan secondary factor. Untuk core factor memiliki bobot $60 \%$, sedangkan secondary factor memiliki bobot $40 \%$. Core factor dan secondary factor ditentukan berdasarkan sub kriteria yang paling diprioritaskan. Keluaran yang nantinya dihasilkan adalah urutan alternatif dari yang tertinggi sampai terendah.

\subsection{Pemetaan Gap Kompetensi}

Gap yang dimaksud disini adalah perbedaan /selisih value masing masing aspek/atribut dengan value target

Tabel 2.1 Tabel Bobot Nilai Gap

\begin{tabular}{|c|c|l|}
\hline Selisih & Bobot Nilai & \multicolumn{1}{|c|}{ Keterangan } \\
\hline 0 & 5 & $\begin{array}{l}\text { Tidak ada selisih (Kompetensi sesuai } \\
\text { yang dibutuhkan) }\end{array}$ \\
\hline 1 & 4.5 & $\begin{array}{l}\text { Kompetensi individu kelebihan 1 } \\
\text { tingkat/level }\end{array}$ \\
\hline-1 & 4 & $\begin{array}{l}\text { Kompetensi individu kekurangan 1 } \\
\text { tingkat/level }\end{array}$ \\
\hline 2 & 3.5 & $\begin{array}{l}\text { Kompetensi individu kelebihan 2 } \\
\text { tingkat/level }\end{array}$ \\
\hline-2 & 3 & $\begin{array}{l}\text { Kompetensi individu kekurangan 2 } \\
\text { tingkat/level }\end{array}$ \\
\hline 3 & 2.5 & $\begin{array}{l}\text { Kompetensi individu kelebihan 3 } \\
\text { tingkat/level }\end{array}$ \\
\hline-3 & 2 & $\begin{array}{l}\text { Kompetensi individu kekurangan 3 } \\
\text { tingkat/level }\end{array}$ \\
\hline 4 & 1.5 & $\begin{array}{l}\text { Kompetensi individu kelebihan 4 } \\
\text { tingkat/level }\end{array}$ \\
\hline-4 & 1 & $\begin{array}{l}\text { Kompetensi individu kekurangan 4 } \\
\text { tingkat/level }\end{array}$ \\
\hline
\end{tabular}

\subsection{Perhitungan pengelompokan Core dan} Secondary Factor

Setelah menentukan bobot nilai gap untuk semua aspek dengan cara yang sama, setiap aspek dibagi lagi menjadi dua kelompok yaitu kelompok Core Factor dan Secondary Factor.

Perhitungan Core Factor dapat ditunjukkan pada persamaan dibawah ini :

$\mathrm{NCF}=\frac{\Sigma \mathrm{NC}}{\Sigma \mathrm{IC}}$

Keterangan :
NCF : Nilai rata rata Core Factor

NC : Jumlah total nilai Core Factor

IC : jumlah item Core Factor

Perhitungan Secondary Factor dapat ditunjukkan pada persamaan dibawah ini :

$\mathrm{NSF}=\frac{\Sigma \mathrm{SC}}{\Sigma \mathrm{IS}}$

Keterangan :

NSF : Nilai rata rata Secondary Factor

NS : Jumlah total nilai Secondary Factor

IS : jumlah item Secondary Factor

\subsection{Penghitungan Nilai Total}

Dari perhitungan Core Factor dan Secondary Factor dari tiap tiap aspek, kemudian dihitung nilai total dari setiap aspek yang diperkirakan berpengaruh pada kinerja setiap profil.

Perhitungan Nilai Total dapat ditunjukkan pada persamaan dibawah ini :

$\begin{array}{ll} & \mathrm{N}=(\mathrm{X}) \% \mathrm{NCF}+(\mathrm{X}) \% \mathrm{NSF} \\ & \text { Keterangan } \quad: \\ \mathrm{N} & \text { : nilai total tiap aspek } \\ \mathrm{NCF} & \text { : Nilai rata rata core factor } \\ \mathrm{NSF} & \text { : Nilai rata rata secondary factor } \\ (\mathrm{X}) \% & \text { : Nilai presentase yang diinputkan }\end{array}$

\subsection{Penghitungan Perankingan}

Hasil akhir dari proses profile matching adalah rangking dari kandidat yang diajukan untuk mengisi suatu jabatan/posisi tertentu.

Perhitungan Nilai Total dapat ditunjukkan pada persamaan dibawah ini :

$$
\text { Ranking }=70 \% \mathrm{NCF}+30 \% \mathrm{NSF}
$$

$\begin{array}{ll}\text { Keterangan } & : \\ \text { NCF } & : \text { Nilai core factor } \\ \text { NSF } & : \text { Nilai secondary factor }\end{array}$

\subsection{Contoh kasus penyeleksian karyawan}

\subsubsection{Kriteria yang dibutuhkan}

Tabel 2.2 Tabel Kriteria

\begin{tabular}{|l|c|}
\hline Kriteria & Bobot (\%) \\
\hline Kecerdasan & 50 \\
\hline Sikap Kerja & 25 \\
\hline Perilaku & 25 \\
\hline
\end{tabular}


2.4.2. Penentuan Nilai Kriteria, Core Factor dan Secondary Factor

Tabel 2.3 Tabel Nilai Kriteria, Core Factor dan Secondary Factor

\begin{tabular}{|c|c|c|c|}
\hline No & Kriteria & Core Factor & Secondary Factor \\
\hline \multicolumn{4}{|c|}{ Aspek Kecerdasan } \\
\hline 1 & Kecerdasan (4) & $x$ & \\
\hline 2 & Verbalisasilde (3) & & $\mathrm{x}$ \\
\hline 3 & Sistematika Berfikir (4) & $\mathrm{x}$ & \\
\hline 4 & Kemampuan Penalaran (4) & $x$ & \\
\hline 5 & Konsentrasi (3) & $\mathrm{x}$ & \\
\hline 6 & Logika (4) & $\mathrm{x}$ & \\
\hline 7 & Fleksibilitas Berfikir (4) & & $\mathrm{x}$ \\
\hline 8 & Imajinasi Kreatif (5) & & $x$ \\
\hline 9 & Antisipasi(3) & & $\mathrm{x}$ \\
\hline 10 & Potensi Kecerdasan (4) & & $x$ \\
\hline \multicolumn{4}{|c|}{ Aspek Sikap Kerja } \\
\hline 1 & Energi Psikis (3) & & \\
\hline 2 & Ketelitian dan tanggung jawab (4) & $\mathrm{x}$ & \\
\hline 3 & Kehati hatian (2) & $x$ & \\
\hline 4 & Pengendalian Perasaan (3) & & $\mathrm{x}$ \\
\hline 5 & Dorongan prestasi (3) & $\mathrm{x}$ & \\
\hline 6 & Vitalitas perencanaan (5) & & $x$ \\
\hline \multicolumn{4}{|c|}{ Aspek Perilaku } \\
\hline 1 & Kekuasaan (3) & & $x$ \\
\hline 2 & Pengaruh (3) & & $\bar{x}$ \\
\hline 3 & Keteguhan Hati (4) & $x$ & \\
\hline 4 & Pemenuhan (5) & $\mathrm{x}$ & \\
\hline
\end{tabular}

\subsubsection{Hasil Gap terhadap lima orang pelamar}

Tabel 2.4 Tabel hasil perhitungan Gap untuk aspek kecerdasan

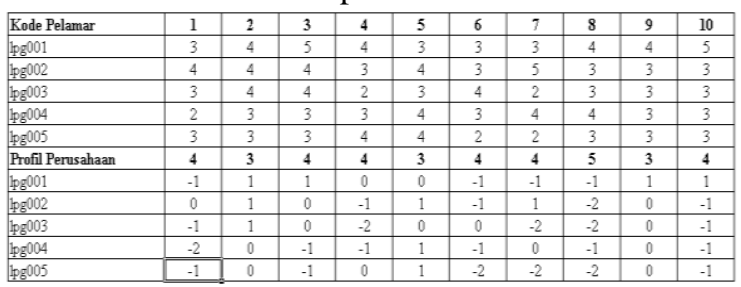

Tabel 2.5 Tabel hasil perhitungan Gap untuk Sikap Kerja

\begin{tabular}{|l|c|c|c|c|c|c|}
\hline Kode Pelamar & $\mathbf{1}$ & $\mathbf{2}$ & $\mathbf{3}$ & $\mathbf{4}$ & $\mathbf{5}$ & $\mathbf{6}$ \\
\hline $\operatorname{lpg} 001$ & 3 & 4 & 5 & 4 & 3 & 3 \\
\hline $\operatorname{lpg} 002$ & 4 & 4 & 4 & 3 & 4 & 3 \\
\hline $\operatorname{lpg} 003$ & 3 & 4 & 4 & 2 & 3 & 4 \\
\hline $\operatorname{lpg} 004$ & 2 & 3 & 3 & 3 & 4 & 3 \\
\hline $\operatorname{lpg} 005$ & 3 & 3 & 3 & 4 & 4 & 2 \\
\hline Profil Perusahaan & $\mathbf{3}$ & $\mathbf{4}$ & $\mathbf{2}$ & $\mathbf{3}$ & $\mathbf{3}$ & $\mathbf{5}$ \\
\hline $\operatorname{lpg} 001$ & 0 & 0 & 3 & 1 & 0 & -2 \\
\hline $\operatorname{lpg} 002$ & 1 & 0 & 2 & 0 & 1 & -2 \\
\hline $\operatorname{lpg} 003$ & 0 & 0 & 2 & -1 & 0 & -1 \\
\hline $\operatorname{lpg} 004$ & -1 & -1 & 1 & 0 & 1 & -2 \\
\hline $\operatorname{lpg} 005$ & 0 & -1 & 1 & 1 & 1 & -3 \\
\hline
\end{tabular}

Tabel 2.6 Tabel hasil perhitungan Gap untuk Perilaku

\begin{tabular}{|l|c|c|c|c|}
\hline Kode Pelamar & $\mathbf{1}$ & $\mathbf{2}$ & $\mathbf{3}$ & $\mathbf{4}$ \\
\hline 1pg001 & 4 & 2 & 3 & 3 \\
\hline $\operatorname{lpg} 002$ & 2 & 3 & 4 & 3 \\
\hline $\operatorname{lpg} 003$ & 4 & 3 & 3 & 2 \\
\hline $\operatorname{lpg} 004$ & 2 & 4 & 4 & 2 \\
\hline $\operatorname{lpg} 005$ & 3 & 4 & 2 & 2 \\
\hline Profil Perusahaan & $\mathbf{3}$ & $\mathbf{3}$ & $\mathbf{4}$ & $\mathbf{5}$ \\
\hline lpg001 & 1 & -1 & -1 & -2 \\
\hline $\operatorname{lpg} 002$ & -1 & 0 & 0 & -2 \\
\hline $\operatorname{lpg} 003$ & 1 & 0 & -1 & -3 \\
\hline $\operatorname{lpg} 004$ & -1 & 1 & 0 & -3 \\
\hline $\operatorname{lpg} 005$ & 0 & 1 & -2 & -3 \\
\hline
\end{tabular}

Setelah dihasilkan gap dari masing masing kriteria diatas maka selanjutnya menentukan bobot nilai dan menentukan serta menghitung faktor faktor yang menjadi core dan secondary factor seperti disajikan pada tabel dibawah ini :

Tabel 2.7 Tabel Bobot, Core Factor dan Secondary Factor aspek Kecerdasan

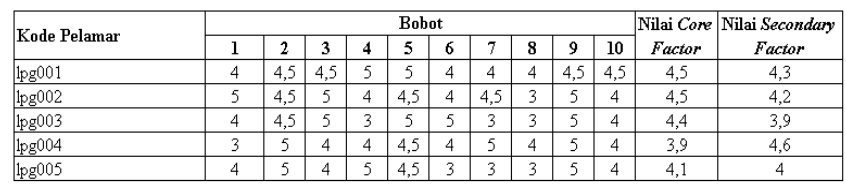

Tabel 2.8 Tabel Bobot, Core Factor dan Secondary Factor Sikap Kerja

\begin{tabular}{|c|c|c|c|c|c|c|c|c|}
\hline \multirow{2}{*}{ Kode Pelamar } & \multicolumn{6}{|c|}{ Bobot } & \multirow{2}{*}{$\begin{array}{l}\text { Nilai } \\
\text { Core }\end{array}$} & \multirow{2}{*}{$\begin{array}{c}\text { Nilai } \\
\text { Secondary }\end{array}$} \\
\hline & 1 & 2 & 3 & 4 & 5 & 6 & & \\
\hline $\operatorname{lpg} 001$ & 5 & 5 & 2,5 & 4,5 & 5 & 3 & 4,2 & 4,2 \\
\hline $\operatorname{lpg} 002$ & 4,5 & 5 & 3,5 & 5 & 4,5 & 3 & 4,3 & 4,2 \\
\hline $\operatorname{lpg} 003$ & 5 & 5 & 3,5 & 4 & 5 & 4 & 4,5 & 4,3 \\
\hline $\operatorname{lpg} 004$ & 4 & 4 & 4,5 & 5 & 4,5 & 3 & 4,3 & 4,0 \\
\hline $\operatorname{lpg} 005$ & 5 & 4 & 4,5 & 4,5 & 4,5 & 2 & 4,3 & 3,8 \\
\hline
\end{tabular}

Tabel 2.9 Tabel Bobot, Core Factor dan Secondary Factor Sikap Kerja

\begin{tabular}{|c|c|c|c|c|c|c|}
\hline \multirow{2}{*}{ Kode Pelamar } & \multicolumn{4}{|c|}{ Bobot } & \multirow{2}{*}{$\begin{array}{l}\text { Nilai } \\
\text { Core }\end{array}$} & \multirow{2}{*}{$\begin{array}{c}\text { Nilai } \\
\text { Secondar }\end{array}$} \\
\hline & 1 & 2 & 3 & 4 & & \\
\hline $\operatorname{lpg} 001$ & 4,5 & 4 & 4 & 3 & 3,5 & 4,3 \\
\hline $\operatorname{lpg} 002$ & 4 & 5 & 5 & 3 & 4,0 & 4,5 \\
\hline $\operatorname{lpg} 003$ & 4,5 & 5 & 4 & 2 & 3,0 & 4,8 \\
\hline lpg004 & 4 & 4,5 & 5 & 2 & 3,5 & 4,3 \\
\hline $\operatorname{lpg} 005$ & 5 & 4,5 & 3 & 2 & 2,5 & 4,8 \\
\hline
\end{tabular}

Setelah perhitungan core factor dan secondary factor selesai, maka langkah selanjutnya adalah melakukan perhitungan nilai total dari kriteria tersebut dimana proses perhitungan nilai total atas kriteria yang ada dapat dilihat pada tabel berikut :

Tabel 2.10 Tabel perhitungan Nilai Total Aspek Kecerdasan

\begin{tabular}{|l|c|c|c|}
\hline Kode Pelamar & $\begin{array}{c}\text { Nilai Core } \\
\text { Factor }\end{array}$ & $\begin{array}{c}\text { Nilai Secondary } \\
\text { Factor }\end{array}$ & Nilai Total \\
\hline $\operatorname{lpg} 001$ & 4,5 & 4,3 & 4,4 \\
\hline $\lg 0002$ & 4,5 & 4,2 & 4,4 \\
\hline $\operatorname{lpg} 003$ & 4,4 & 3,9 & 4,2 \\
\hline $\operatorname{lpg} 004$ & 3,9 & 4,6 & 4,2 \\
\hline $\operatorname{lpg} 005$ & 4,1 & 4 & 4,1 \\
\hline
\end{tabular}


Tabel 2.11 Tabel perhitungan Nilai Total Aspek Sikap Kerja

\begin{tabular}{|l|c|c|c|}
\hline Kode Pelamar & $\begin{array}{c}\text { Nilai } \\
\text { Core }\end{array}$ & $\begin{array}{c}\text { Nilai } \\
\text { Secondary }\end{array}$ & $\begin{array}{c}\text { Nilai } \\
\text { Total }\end{array}$ \\
\hline lpg001 & 4,2 & 4,2 & 4,2 \\
\hline lpg002 & 4,3 & 4,2 & 4,3 \\
\hline lpg003 & 4,5 & 4,3 & 4,4 \\
\hline lpg004 & 4,3 & 4,0 & 4,2 \\
\hline lpg005 & 4,3 & 3,8 & 4,1 \\
\hline
\end{tabular}

Tabel 2.12 Tabel perhitungan Nilai Total Aspek Perilaku

\begin{tabular}{|l|c|c|c|}
\hline Kode Pelamar & $\begin{array}{c}\text { Nilai } \\
\text { Core }\end{array}$ & $\begin{array}{c}\text { Nilai } \\
\text { Secondar }\end{array}$ & $\begin{array}{c}\text { Nilai } \\
\text { Total }\end{array}$ \\
\hline $\operatorname{lpg} 001$ & 3,5 & 4,3 & 3,8 \\
\hline $\operatorname{lpg} 002$ & 4,0 & 4,5 & 4,2 \\
\hline $\operatorname{lpg} 003$ & 3,0 & 4,8 & 3,7 \\
\hline $\operatorname{lpg} 004$ & 3,5 & 4,3 & 3,8 \\
\hline $\operatorname{lpg} 005$ & 2,5 & 4,8 & 3,4 \\
\hline
\end{tabular}

Setelah didapatkan nilai total, maka langkah yang terakhir adalah membuat suatu perangkingan yang dapat dilihat pada tabel berikut :

Tabel 2.13 Tabel perhitungan Nilai Total Aspek Perilaku

\begin{tabular}{|l|c|c|c|c|}
\hline Kode Pelamar & Nilai Aspek Kecerdasan & Nilai Aspek Sikap kerja & Nilai Aspek Perilaku & Perankingan \\
\hline $\lg 001$ & 4,4 & 4,2 & 3,8 & 4,20 \\
\hline $\lg 002$ & 4,4 & 4,3 & 4,2 & 4,33 \\
\hline $\lg 0003$ & 4,2 & 4,4 & 3,7 & 4,13 \\
\hline $\lg 0004$ & 4,2 & 4,2 & 3,8 & 4,10 \\
\hline $\log 005$ & 4,1 & 4,1 & 3,4 & 3,93 \\
\hline
\end{tabular}

\section{Kesimpulan}

Dalam penelitian yang telah dilakukan maka kesimpulan yang diperoleh untuk menjawab pertanyaan dari rumusan masalah bahwa dengan dibuatnya sistem penunjang keputusan akan mempermudah pihak manajemen dan tim panitia seleksi dalam mendapatkan informasi yang sesuai dengan kebutuhan dengan menggunakan metodelogi yanng digunakan pada penelitian ini yang disesuaikan dengan kebutuhan penggunanya. Dengan sistem penunjang keputusan ini pihak manajemen dan tim panitia seleksi akan lebih mudah melihat hasil dari penyeleksian beasiswa berdasarkan kriteria dan subkriteria yang telah di tentukan.

\section{Daftar Pustaka}

[1] Bambang Hartono, Sistem Informasi Manajemen Berbasis Komputer, Edisi Pertama, Jakarta : PT Rineka Cipta, 2013.

[2] Kusrini, Konsep dan Aplikasi Sistem Pendukung Keputusan, Edisi Pertama, Yogyakarta: CV Andi Offset, 2007.

[3] Maharrani, Ratih Hafsarah. "Penerapan Metode Analytical Hierarchi Process Dalam Penerimaan Karyawan Pada PT. Pasir Besi Indonesia". Jurnal Teknologi Informasi, Vol. 6, (April 2010) $: 4$.

[4] Marimin, Magfiroh, Aplikasi Teknik Pengambilan Keputusan dalam Manajemen Rantai Pasok, Edisi Keempat, Bogor : PT Penerbit IPB Press, 2010.

[5] Rekrutmen Sumber Daya Manusia, silfi.staff.gunadarma.ac.id/.../3_RekruitmenSumber-Daya-Manusia.pdf (diakses pada 128 Mei 2017)

[6] Undang-undang Republik Indonesia No.13 Tahun 2003. www.hukumonline.com. (Diakses 8 Mei 2017) 